\title{
Las primeras fases de ocupación islámica de Marroquíes Bajos (Jaén)
}

Juan Carlos Castillo Armenteros *

\section{INTRODUCCIÓN}

En este trabajo recogemos algunos de los primeros resultados, que sobre la ocupación de la periferia de la ciudad de Jaén durante la época islámica, están aportando las excavaciones arqueológicas de urgencia de Marroquíes Bajos.

Nuestro estudio surgió a partir de un acuerdo de colaboración entre los miembros del Área de Historia Medieval de la Universidad de Jaén, la Dirección del Proyecto Arqueológico del Casco Urbano de Jaén y los técnicos de la Delegación Provincial de Cultura de la Junta de Andalucía. Su objetivo era estudiar algunas estructuras, presumiblemente islámicas, que aparecieron tras los primeros trabajos de excavación arqueológica y de destierro mecánico, efectuados en una de las parcelas en vías de construcción de Marroquíes Bajos.

Los trabajos de excavación se desarrollaron durante los meses de septiembre y octubre de 1995, participando en la misma alumnos de la Licenciatura de Humanidades de la Universidad de Jaén y obreros de la Empresa Constructora Mesa-Castillo!

\section{LA EXCAVACIÓN ARQUEOLÓGICA}

La zona de estudio se encuentra situada en la periferia del actual casco urbano de la ciu- dad de Jaén, dentro de una de las áreas de expansión urbana situadas al Norte del mismo (Fig. I). El solar excavado se ubica en la zona de Marroquíes Bajos, concretamente en uno de los polígonos de urbanización (RP-4, Parcela G-3) situado entre la Estación del Ferrocarril y la Carretera de Madrid (Fig. 2).

Como hemos indicado, en dicha parcela se venían desarrollando distintos estudios arqueológicos centrados principalmente, en el análisis y documentación de niveles de ocupación de la Edad del Cobre. E incluso se efectuó un destierro mecánico de buena parte del solar, cuyo objetivo había sido eliminar aquellos estratos más superficiales, los cuales fueron creados por procesos de deposición y arrastre durante los últimos siglos, épocas en la que se utilizó la zona como huertas, y posteriormente, como área de vertederos incontrolados.

La localización con la máquina excavadora de algunas estructuras y niveles arqueológicos determino que el destierro se limitara a eliminar una amplia capa de tierra de color oscuro, muy homogénea, compuesta básicamente por materia orgánica, que con toda probabilidad se formó durante los años que la zona constituyó uno de los espacios de huertas más importantes de Jaén a partir del siglo XVI. De esta manera, el destierro se paralizó a una cota determinada, dejando en algunas zonas en superficie, la fase de ocupación islámica, mientras que en otras lo

\footnotetext{
* Universidad de Jaén. Área de $\mathrm{H}^{\mathrm{a}}$ Medieval. Grupo de Investigación del Patrimonio Arqueológico de Jaén.

I A todos ellos mi más sincero agradecimiento, especialmente a Da Sonia Pérez, Da Consuelo Diez, D. Juan Rafael Montilla, Da Teresa Campos y D Gregorio Rama Moral.
} 
eran los niveles de la Edad del Cobre. No obstante, en aquellas áreas donde se detectaron niveles o estructuras arqueológicas, el destierro se paralizó, quedando sin afectar las zonas circundantes, con el fin de evitar dañarlos y conservar una estratigrafía lo más completa posible.

A pesar de que estas labores se hicieron con el mayor cuidado posible, no cabe duda, y así quedó demostrado durante la excavación, que algunas de las estructuras fueron dañadas con los trabajos mecánicos.

A la fase de ocupación islámica corresponden diversas estructuras con márgenes cronológicos distintos; la más antigua corresponde a dos plataformas de planta circular (Lám. I), documentadas en los trabajos de excavación dirigidos por D. Cristóbal Pérez, D. Eduardo Penedo y $D^{a}$ Monserrat Llorente ${ }^{2}$. La segun$\mathrm{da}$, con los restos de un edificio, y otros elementos asociados al mismo, como fosas y vertederos, pozos, etc. situados en torno al mismo, que fueron los excavados por nosotros (Fig. 4).

Nuestra intervención se desarrollo exclusivamente en el límite Sur del solar, que era la zona menos afectada por los trabajos de destierro. Con el objetivo de abarcar la mayor parte de la zona que superficialmente presentaban los niveles islámicos, se trazaron tres amplios cortes, dos de ellos con una dimensión de $17 \times 8 \mathrm{~m}$. y otro de $17 \times 7 \mathrm{~m}$.) ${ }^{3}$.

\section{LAS ESTRUCTURAS ISLÁMICAS}

Como hemos indicado, la intervención arqueológica sacó a la luz diversas estructuras de época islámica, el estudio de la secuencia estratigráfica y de las estructuras, nos muestra tres momentos de ocupación diferentes:

\section{Las Primeras Estructuras}

La fase de ocupación más antigua, podríamos datarla entre los siglos VIII y IX, se corres- ponde con dos estructuras de planta circular, con unas dimensiones aproximadas de $2.60 \times$ 2.20 m. Su construcción se efectuó excavando en los niveles de ocupación anteriores, una amplia fosa de $3.5 \times 3 \mathrm{~m}$. de longitud, hasta alcanzar la base geológica. La excavación de esta fosa, supuso la destrucción de diversas estructuras de la Edad del Cobre. Una vez realizada la fosa se rellenó con varias capas alternativas de greda (extraída de la base geológica) y tierra apisonada, quedando finalmente todo este conjunto nivelado y cubierto con una última capa de greda y piedras de pequeño tamaño. En esta plataforma se excavaron varios hoyos de poste, en los que se introducirín vigas de made$\mathrm{ra}$, que fueron calzadas con pequeñas cuñas de piedra, de ellos tan sólo se han conservado dos (Lám. I), ya que estas estructuras han sido alteradas por las cimentaciones de los edificios de la siguiente fase de ocupación.

Junto a estas estructuras, y posiblemente relacionadas con ellas, se han documentado tramos de varios canales de pequeñas dimensiones, que con dirección Este - Oeste, fueron construidos excavando y destruyendo niveles de ocupación de la Edad del Cobre.

Ambas estructuras habría que relacionarlas con una actividad agrícola, constituyendo la primera una cimentación sobre la que pudo levantarse un pequeño almacén de madera o granero, y las segundas canales de riego, que trasladarían el agua extraída de un pozo o desviada de un arroyo, a los campos de cultivo.

\section{La Vivienda}

A la segunda fase de ocupación pertenece un edificio de planta rectangular, definido por un patio de gran tamaño y una nave lateral (Fig. 4). El patio posee unas dimensiones de 14 $\mathrm{m}$. de largo por $7 \mathrm{~m}$. de ancho, estando compartimentado en dos espacios, de similares proporciones $(7 \times 7 \mathrm{~m}$.). Su excavación no documentó indicios de ningún tipo de pavimentación, por lo que suponemos que esta sería de tierra.

\footnotetext{
2 A quienes agradecemos el interés mostrado por nuestro trabajo, y la cesión de la información obtenida en sus trabajos de excavación. 3 Los datos sobre la propia excavación y la metodología empleada pueden consultarse en el informe de la misma PÉREZ Y CASTILLO (En prensa).
} 
De los dos espacios que configuran el patio, el primero de ellos, el ubicado al Norte, posiblemente no aparecería cerrado por su lateral Norte, formando de esta manera un área cuadrada abierta al exterior. Desde este se accedía al interior de segundo espacio, el patio de la vivienda propiamente dicho. El acceso se efectuaba a través de una puerta ubicada en el muro Sur, de la que no se han conservado restos, al estar esta zona muy afectada por los trabajos de destierro mecánico.

Adosada al muro Este de ambas zonas abiertas se construyó un edificio de planta rectangular, con unas dimensiones de $14 \times 3 \mathrm{~m}$. A su interior se accedía desde el patio, a través de una puerta ubicada en el muro Este, de la cual aún se conservan varias losas que serían utilizadas como el escalón o quicio de la puerta.

Este edificio pudo estar compartimentado en dos estancias, a juzgar por la aglomeración de derrumbes de piedra documentados durante su excavación en la zona central (Lám. 2, Fig. 4).

Estas dos habitaciones no son simétricas, existiendo una de menor tamaño, de planta cuadrada, situada en la zona Norte, quedando las de mayores dimensiones, de planta rectangular, al Sur de la anterior. Ambas comunicarían a través de una puerta, situada en el muro de compartimentación.

Tanto estas dependencias como los espacios de patio, fueron construidos con muros de tapial de tierra sobre basamento de mampostería. La tierra empleada para la fabricación de los tapiales, fue obtenida de las inmediaciones, para ello se arrasaron niveles de ocupación anteriores, de ahí que en los distintos estratos y niveles de ocupación, la cerámica de este período aparezca mezclada con fragmentos muy erosionados de la Edad del Cobre, así como algunos ibéricos y romanos. Las fosas creadas para la extracción de la tierra fueron utilizadas como vertederos y muladares.
Este edificio se cubrió con una techumbre de tejas, no pudiéndose determinar si lo era a un agua o a dos, ya que los niveles islámicos se encontraban sumamente erosionados y alterados, como lo confirma la desaparición de algunos tramos de muro, y el que de estas estructuras tan solo conservaba el nivel de cimentación. El pavimento de estas habitaciones tuvo que ser muy similar al del patio, tierra apisonada.

Al extenderse las estructuras de hábitat hacia el Sur del solar, continuando fuera de la parcela a urbanizar, concretamente en una zona reservada a vía pública, no pudimos documentar el cierre de las dependencias y del patio, y por tanto, resultó imposible determinar las dimensiones reales de esta casa. No obstante, posteriores trabajos de seguimiento de obras de acondicionamiento y canalización de la calle ${ }^{4}$, han confirmado su cerramiento en esta zona. A pesar de ello, tampoco podemos obviar la posibilidad de que existiera otra dependencia transversal, que cerrara el edificio por su lado Sur.

La excavación arqueológica constató una tercera fase de ocupación que consistió en una importante transformación de la vivienda y de su entorno más inmediato.

El edificio analizado presentaba claras evidencias de haber sufrido un derrumbamiento, siendo reparado de forma significativa. Las obras de reparación se constatan en la reconstrucción total del muro que por el Norte cerraba la pequeña habitación de planta cuadrada. Este muro fue construido aprovechando parte de la cimentación del anterior, sobre la que se levanta un nuevo cimiento de piedras de pequeño tamaño, con abundante argamasa de tierra y cal. Este mismo tipo de argamasa fue utilizado para pavimentar ambas habitaciones, a juzgar por los escasos restos conservados.

Otros indicios de las obras de reconstrucción del edificio son las distintas fosas basure4 Obras realizadas por el Excmo. Ayuntamiento de Jaén, bajo la dirección y supervisión de los arqueólogos, Da María del Carmen
Pérez y D. José Luis Serrano. 
ro, que tan solo contienen materiales de construcción, tejas enormemente fragmentadas y algunas piedras de pequeño tamaño. Estas fosas tienen planta casi circular, con unas dimensiones de $2 \times 1.75 \mathrm{~m}$. y una profundidad de 50 $\mathrm{cm}$. Junto a ellas, en el Corte 32 , se documentó una gran fosa con abundante material de construcción muy fragmentado, y un apilamiento de tejas bien conservadas, colocadas en dos hiladas. Con toda probabilidad, fueron depositadas de esta forma, como material de construcción rescatado del derrumbe y preparado para ser utilizado en el nuevo edificio en caso de necesidad (Fig. 4; Lám. 3).

Finalmente, las reestructuraciones internas del edificio también se observan en el cerramiento de algunos vanos, como el efectuado en la puerta que comunica la dependencia rectangular con el patio de la casa. Para obstruir la comunicación entre los dos espacios, se colocó en este vano una gran tinaja (Lám. 4), trasladándose la puerta a otra zona del edificio.

Las semejanzas que presenta el material empleado para la reconstrucción del muro y la pavimentación de las dependencias, con los pavimentos y estructuras documentados en otras zonas de Marroquíes Bajos, nos indican, que la reedificación de esta casa se produce a finales del siglo $X$, período al que según sus excavadores habría que adscribir las viviendas documentadas en los solares próximos (SERRANO, 1997).

\section{Otras Estructuras}

Relacionadas con las últimas fases de ocupación de la zona estudiada se documentaron otras estructuras, que nos permiten establecer e interpretar las funciones que tuvo el edificio y las transformaciones que este sufrió mientras estuvo habitado.

En torno a la vivienda, y siempre en el exterior, se han documentado varias fosas (Lám. 5) y vertederos, donde fueron depositadas gran cantidad de desechos, compuestos por restos oseos animales, materia orgánica, tejas y algunos reci- pientes muy fragmentados de toda índole (Fig. 7 y 8). El material cerámico depositado en todas estas fosas es bastante homogéneo, destacando la ausencia casi total de elementos vidriados (Fig. 8-f). La enorme similitud de tipos y de las formas, nos indica que todas ellas pudieron crearse en períodos cronológicos muy próximos. No obstante, la presencia en una de ellas (C.E. 17) de un fragmento de ataurique (Fig. 7-K) nos indica que esta fosa pertenecería al segundo momento constructivo del edificio.

Así mismo, en los trabajos de excavación y de destierro mecánico, dirigidos por $D^{a}$ Monserrat Llorente, localizaron en el borde Este del solar, el extremo de un pozo de gran tamaño, que se extendía hacia una zona destinada a vía pública en los proyectos de urbanización de la zona. Ello impidió documentar con mayor precisión la planta y los niveles de deposición.

Su construcción se realizó excavando un pozo de $2.20 \mathrm{~m}$. de diámetro en la base geológica, revistiéndose a continuación todo el perímetro de la fosa con un muro de mampostería, ocupando la parte más externa del muro hiladas de gran tamaño, mientras que el espacio intermedio creado entre dicho muro y la base geológica, fue rellenado con piedras de pequeño tamaño. El resultado final, fue un pozo con unas dimensiones aproximadas de $2.5 \mathrm{~m}$. de profundidad y $1.30 \mathrm{~m}$. de anchura (Fig. 5; Lám. 6) $)^{5}$, que la define como una estructura muy diferente a otra serie de pozos documentados en este solar o en otras zonas de Marroquíes, por lo general con dimensiones más reducidas. Ello, nos permite suponer, que dado su tamaño, $y$ teniendo en cuenta que lo documentado tan sólo es el extremo del mismo, se trataría del pozo de una noria. Esta hipótesis, adquiere mayor solidez, al comprobar que entre los materiales cerámicos documentados en el edificio y en las fosas vertedero próximas, aparecen distintos fragmentos de cangilones $\mathrm{O}$ arcaduzes de Noria (Fig. 7-G, H, I; 8-A; I0-A). Su tamaño y sus características la asemejan al pozo de noria analizado por A. Bazzana, S. Climent y Y. Montmessin (1987) en el yacimiento de Les Jovades.

\footnotetext{
5 Datos y dimensiones obtenidos de los dibujos cedidos generosamente por Da Monserrat Llorente.
} 


\section{EL MATERIAL CERÁMICO}

El análisis del material cerámico define un margen cronológico muy amplio, datable entre los siglos VIII y X. No obstante, el estudio pormenorizado del mismo, dentro de sus correspondientes niveles estratigráficos, nos permite adscribirlo a cada una de las fases de ocupación constatadas en el solar.

El material cerámico más antiguo, datable entre los siglos VIII y IX, corresponde a las estructuras circulares documentadas en la primera fase de ocupación. En él destaca la total inexistencia de material vidriado, predominando los recipientes cerámicos elaborados a mano/torneta, con características muy similares a los documentados en el Cerro de Peñaflor (CASTILLO, 1996b). En estos recipientes predominan las pastas oscuras con abundante desgrasante mineral, destacando las ollas (Fig. 6-B, E) y los jarros de vertedera (Fig. 6-C, D). Así mismo, dentro de la serie jarro, también se han documentado algunos ejemplares modelados a torno, con pastas claras y motivos decorativos de líneas horizontales o verticales en almagra o manganeso. Finalmente, se han registrado varios fragmentos de candiles de cazoleta $y$ piquera de pequeñas proporciones (Fig. 6-A).

En los niveles arqueológicos relacionados con la zona de hábitat documentada en la segunda fase de ocupación del solar, se han recogido materiales cerámicos que pueden datarse entre los siglos IX y X. Presentando características formales y tipológicas similares a los extraídos en los asentamientos de Peñaflor y Cerro Miguelico (SALVATIERRA Y CASTILLO, 1993). Los cambios más significativos que se aprecian dentro de la muestra, son la presencia, aunque con porcentajes mínimos, de recipientes vidriados (Fig. 9-C), y la mayor abundancia de materiales elaborados a torno. Entre los tipos más numerosos, caben destacar los recipientes de mesa, como jarros y jarras, realizados a torno (Fig. 9-B, F, I; I0-I, J), y decorados con líneas verticales en rojo o negro (Fig. 10-H). Así como, los recipientes de cocina, destacando las ollas, modeladas tanto a torno, como a mano y torneta (Fig. 9-H; IO-E, F, G), siendo frecuentes las ollas trípode (Fig. 9-E, G), típicas de la Campi- ña de Jaén durante este período cronológico (CASTILLO, 1996a y b). Este tipo de olla, incorpora en su base tres vástagos, que permitían, a la hora de proceder a la cocción de los alimentos, que la marmita fuese depositada directamente sobre el fuego, sin que se requiriese, para esta función, del empleo de otro artilugio.

Dentro del tipo de recipientes con varios usos, se han documentado varios fragmentos de discos, que pudieron servir para la cocción de alimentos o como tapadera. Todos ellos están modelados a mano, presentando un borde sencillo, sin engrosamientos (Fig. IO-K, L).

También se han recogido fragmentos de una gama variada de recipientes, entre los que cabe destacar a los utilizados para el almacenaje de líquidos o sólidos, tinajas elaboradas a mano, con pastas ocres $y$ abundante desgrasante mineral (Fig. 9-A y 10-B, C), fragmentos de candiles de cazoleta, $y$ arcaduces.

Finalmente, aunque no se ha conservado ningún arcaduz completo, los fragmentos recuperados nos permiten definir su forma, tienen borde apuntado o triangular, cuerpo cilíndrico y estriado, disminuyendo su diámetro al llegar a la base, que suele ser plana (Fig. 7-H, I; 8-A). Presentan dos escotaduras para ser atados a la rueda de la noria, la primera estaría situada bajo el borde del recipiente, y la siguiente en el centro (Fig. 10-A). Estas características formales y tipológicas les sitúa dentro de un tipo de arcaduz muy característico de al-Andalus (BAZZANA ET ALII, 1987; BAZZANA, 1987; BOSCH Y CHINCHILLA, 1987; CARRASCO, 1987; ACIÉN Y MARTÍNEZ, 1989; ACIÉN ET ALII, I99।; CASTLLLO Y MARTÍNEZ, 1993; ROSELLÓ, 1993). Por el contrario muestran características muy diferentes a los catalogados por S. Gutiérrez en la desembocadura del río Segura entre los siglos VII al X (GUTIÉRREZ, 1993; 1996a Y b).

A la última fase de ocupación del edificio, datable en el siglo $X$, corresponde una gama amplia de tipos cerámicos, entre los que abunda una mayor cantidad de recipientes vidriados, destacando por su número los correspondientes a platos o ataifores, que prácticamente están ausentes en los niveles más antiguos. Así mismo, el porcentaje del material a torno supera amplia- 
mente al modelado a mano, predominando también los recipientes de mesa sobre los de almacenaje y cocina.

Dentro de estos niveles, es significativo el número de fragmentos correspondientes a platos o ataifores, todos ellos modelados a torno con pastas claras, muy decantadas, y vidriados en melado, decorando su interior con chorreones de manganeso.

\section{CONSIDERACIONES GLOBALES}

Las características constructivas y las propias dimensiones de este edificio, se asemejan a los excavados en el asentamiento del Cerro de Peñaflor, también datados entre el siglo IX e inicios del X (SALVATIERRA Y CASTILLO, 1991; 1992; 1995). Sin lugar a dudas, el edificio estudiado se identificaría con una construcción rural, que fue edificada con materiales pobres y fácilmente degradables, careciendo de la infraestructura adecuada para el abastecimiento y la evacuación de aguas.

Así mismo, las excavaciones efectuadas en el entorno, nos confirman, que durante las dos fases de ocupación del edificio, la distancia existente con sus vecinos, es lo suficientemente significativa para poder identificarlo con una casa rural aislada, existiendo entre ellas amplios espacios abiertos.

Esta definición como un lugar de hábitat aislado, circundado por muladares exteriores, huertas, norias, etc. nos lleva a identificarla como una ḍay'a o propiedad individual o familiar ubicada en la proximidades de Jaén, la cual, con el objetivo de incrementar la productividad de las zonas de cultivo, aprovecharía tanto las aguas subterráneas, elevadas a través de una noria, como las aguas sobrantes de la ciudad de Jaén, que llegaban a esta zona encauzadas en varios arroyos.

Las prospecciones sistemáticas efectuadas en los últimos años en las inmediaciones de la ciudad de Jaén (CASTILLO ET ALII, 1990; CASTILLO, 1996; ZAFRA ET ALII, En prensa), así como las distintas intervenciones arqueológicas de urgencia desarrolladas en la zona de Marroquíes Bajos (SERRANO, 1997), están constatando la existencia de un importante poblamiento rural, que se distribuiría a lo largo de varios kilómetros alrededor de la ciudad de Jaén. Esta estructura de poblamiento se articulaba en función de la proximidad o abundancia de agua, y de la riqueza de las tierras cultivadas.

En este esquema, el elemento principal que influiría en la organización del espacio ocupado y explotado era el agua, no obstante la forma de obtenerla podía ser diversa, en algunos casos, como el que nos ocupa, una simple noria, sería determinante para definir la zona de hábitat y el área reservada para los campos de cultivo. En otras ocasiones, sería el cauce de un arroyo, el que influiría en el esquema de ocupación, distribuyendo las zonas habitadas y de cultivo entre sus márgenes (SERRANO, 1997). Mientras que en otros, como es el caso de la Imora, otra zona próxima a Jaén, sería un manantial canalizado a través de una conducción subterránea y las albercas de distribución, quienes determinarían el lugar donde se ubicaría el área de residencia y los espacios irrigados.

Finalmente, si comparamos esta importante actividad agrícola, y la estructura de poblamiento que ésta genera, con la situación de la ciudad de Jaén entorno a los siglos IX y X (SALVATIERRA ET ALII, 1993), observamos como los contrastes son significativos. Mientras que la ciudad durante los primeros siglos presenta un nivel de población muy reducido, su entorno más inmediato muestra una situación totalmente distinta.

El despoblamiento de la ciudad tiene su origen en la crisis, que buena parte de las ciudades del alto Guadalquivir sufren a partir del siglo II a. C. (CHOCLAN Y CASTRO, 1987; 1988), situación que se acentúa durante el período visigodo, como consecuencia de las numerosas y graves crisis demográficas ocasionadas por sequías, plagas de langosta y epidemias de peste (GUICHARD, 1976; BARCELó, 1978).

No obstante esta situación cambia a partir de las reformas llevadas a cabo por 'Abd alRaḥmān II, quien consciente de la importante 
riqueza que genera la zona, inicia una importante transformación urbana (AGUIRRE Y SALVATIERRA, 1989) con el fin de imponer sobre la población un sistema fiscal eficaz. En esta línea, traslada la capital de la Cora desde Mentesa (La Guardia) a Ŷayyān (Jaén), inicia un amplio proceso de urbanización de la ciudad, dotándola de importantes elementos defensivos, como lienzos de murallas (CASTILLO Y CANO, En prensa), un posible hișn en la cumbre del Cerro de Santa Catalina (CASTILLO,1995), de mezquitas, Baños, etc. (SALVATIERRA ET ALII, 1993).

\section{BIBLIOGRAFÍA}

ACIÉN, M.; CASTILLO, F.; FERNÁNDEZ, M.I.; MARTÍNEZ, R.; PERAL, C. Y VALLEJO, A. (1995): "Evolución de los tipos cerámicos en el S.E. de al-Andalus". V Colloque Internacional sur le céramique médievale en Mediterranée Occidentale. Rabat.

ACIÉN, M. Y MARTÍNEZ, R. (1989): "Cerámica arcaica del Sureste de al-Andalus". Boletín de Arqueología Medieval Española, 3, Madrid, pp. 123 - 135.

AGUIRRE, F.J. Y SALVATIERRA, V. ( 1989): "Cuando Jaén era Ŷyayān". Jaén, Vol. II, Granada, pp. 453-490.

BARCELÓ, M. (1978): "Les plagues de llagost a la Carpetania". Studis d'Historia Agrária, Vol. I, pp. 67-84.

BAZZANA, A. (1987): "Una noria árabe en la huerta de Oliva (Valencia)". II Congreso de Arqueología Medieval Española, Tomo II, Madrid, pp. 42I-432.

BAZZANA, A.; CLIMENT, S. Y MONTMESSIN, Y. (1987): El yacimiento medieval de Les Jovades - Oliva (Valencia). Oliva.

BOSCH, C. Y CHINCHILLA, M. (1987): "Formas cerámicas auxiliares: anafes, arcaduces y otras". II Congreso de Arqueología Medieval Española. Tomo II, Madrid, pp. 49|-500.

CARRASCO, M.J. (1987): "Avance del estudio de la cerámica hispano-musulmana procedente de los Baños de la Reina Mora (Sevilla)". II Congreso de Arqueología Medieval Española. Tomo II, Madrid, pp. 529-538.

CASTILLO, F. Y MARTÍNEZ, R. (1993): "Producciones cerámicas en Baŷyāana". MALPICA, A. La cerámica altomedieval en el Sur de al-Andalus. Granada, pp. 69-1 16.

CASTILLO, J.C. (1996a): Introducción arqueológica a un proceso histórico. El poblamiento emiral en la Campiña de Jaén. Tesis Doctorales de la Universidad de Jaén. Jaén. Microfichas.

CASTILLO, J.C. (1996b): "La cerámica emiral en la Campiña de Jaén". Arqueología y Territorio Medieval, 3. Jaén, pp. 191-220.
CASTILLO, J.C. (1995): "Las fortificaciones del Cerro de Santa Catalina (Jaén)". El zoco. Vida económica y artes tradicionales en al-Andalus y Marruecos. Barcelona-Madrid, pp. 77-85.

CASTILLO, J.C:; CASTILLO, J.L; LARA, J.C.; MARÍN, M.M. Y PÉREZ, M.C. (1990): "Prospección arqueológica superficial de urgencia en torno a las carreteras nacionales 321 (Úbeda-Málaga) y 324 (Córdoba-Almería". Anuario Arqueológico de Andalucía 1988, Tomo III, Sevilla, pp. 167-172.

CASTILLO, J.L. Y CANO, J. (En prensa): "Diagnosis arqueológica de la muralla Norte de Jaén". Anuario Arqueológico de Andalucía 1993.

CHOCLÁN, C. Y CASTRO, M. (1987): "Ciudad y territorio en la Campiña de Jaén. La distribución de los asentamientos mayores durante la época Flavia". Studia Histórica. Salamanca, pp. 145-160.

CHOCLÁN, C. Y CASTRO, M. (1988): "La Campiña del Alto Guadalquivir en los siglos I - II d. C.. Asentamientos, estructura agraria y mercado". Arqueología Espacial, Vol. 12, Teruel, pp. 205-221.

GUICHARD, P. (1976): Al-Andalus. Estructura antropológica de una sociedad islámica en Occidente. Barcelona.

GUTIÉRREZ, S. (1993): "La cerámica paleoandalusí del Sureste peninsular (Tudmir): Producción y distribución (Siglos VII al X)". MALPICA, A. La cerámica altomedieval en el Sur de al-Andalus. Granada, pp. 38-65.

GUTIÉRREZ, S. ( 1 996a): "El aprovechamiento agrícola de las zonas húmedas: la introducción del arcaduz en el sureste de al-Andalus (siglos VIII - IX)". Arqueología y Territorio Medieval, 3, Jaén, pp. 7-19.

GUTIÉRREZ, S. (1996b): La Cora de Tudmir de la antigüedad tardía al mundo islámico. Poblamiento y cultura material. Madrid-Alicante.

PÉREZ, M.C. Y CASTILLO, J.C. (En prensa): "Informe de intervención arqueológica en los bloques EF - CD de la parcela G del sector R.P.4 en Marroquíes Bajos (Jaén)". Anuario Arqueológico de Andalucía.

ROSELLÓ, G. (1993): "La cerámica de primera época: algunas observaciones metodológicas". MALPICA, M. La cerámica altomedieval del Sur de al-Andalus. Granada, pp. I435.

SALVATIERRA, V. Y CASTILLO, J.C. (199I): "El poblamiento rural ¿histórico o intemporal?. El caso del Arroyo Salado de Jaén". Cuadernos de Madinnat al-Zahrā, Vol. 3, Córdoba, pp. 47-75.

SALVATIERRA, V. Y CASTILLO, J.C. (1992): "EI Cerro de Peñaflor. Un posible asentamiento beréber en la Campiña de Jaén". Anaquel de Estudios Árabes, III, Madrid, pp. |53-|6|.

SALVATIERRA, V. Y CASTILLO, J.C. (I993): "Las cerámicas precalifales de la Cora de Jaén". MALPICA, A. La cerámica altomedieval del Sur de al-Andalus. Granada, pp. 238-258. 
SALVATIERRA, V. y CASTILLO, J.C. (1995): "Peñaflor, un établissement rural d'époque émirale dans la Campiña de Jaén". Archéologie Islamique, 5; pp. II-24.

SALVATIERRA, V.; PÉREZ, M.C.; CASTILLO, J.L; ALCÁZAR, E.M. Y CANO, J. (1993): "Formación y evolución de una ciudad islámica: Jaén". IV Congreso de Arqueología Medieval Española, Tomo II, pp. 87-94.

\section{RESUMEN}

En este estudio presentamos los primeros resultados, que sobre el poblamiento de la periferia de Jaén, durante las primeros siglos de ocupación islámica, están ofreciendo las excavaciones arqueológicas de urgencia de Marroquíes Bajo. En el mismo, se analiza la evolución de una vivienda rural y las diversas estructuras generadas por la intensa explotación agrícola de su entorno más inmediato.

PALABRAS CLAVE: Poblamiento periurbano, siglos VIII al X.
SERRANO, J.L. (1997): "Un complejo Califal de Marroquíes Bajos, (Jaén). Arqueología y Territorio Medieval, 4, Jaén; pp. 59-79.

ZAFRA, J.; SERRANO, J.L;; ROYO, M.A. Y PÉREZ, M.C. (En prensa): "Prospección arqueológica superficial en el suelo urbanizable del termino municipal de Jaén". Anuario Arqueológico de Andalucía 1994.

\section{ABSTRACT}

This paper advances some of the results obtained from the excavations that are currently being carried out on the archaeological phase corresponding to the Islamic occupation of the settlement known as 'Marroquíes Bajos', on the outskirts of Jaén. In particular, we will focus on the evolution of a rural dwelling, as well as on the various structures arisen from the agricultural exploitation of its surrounding area. 


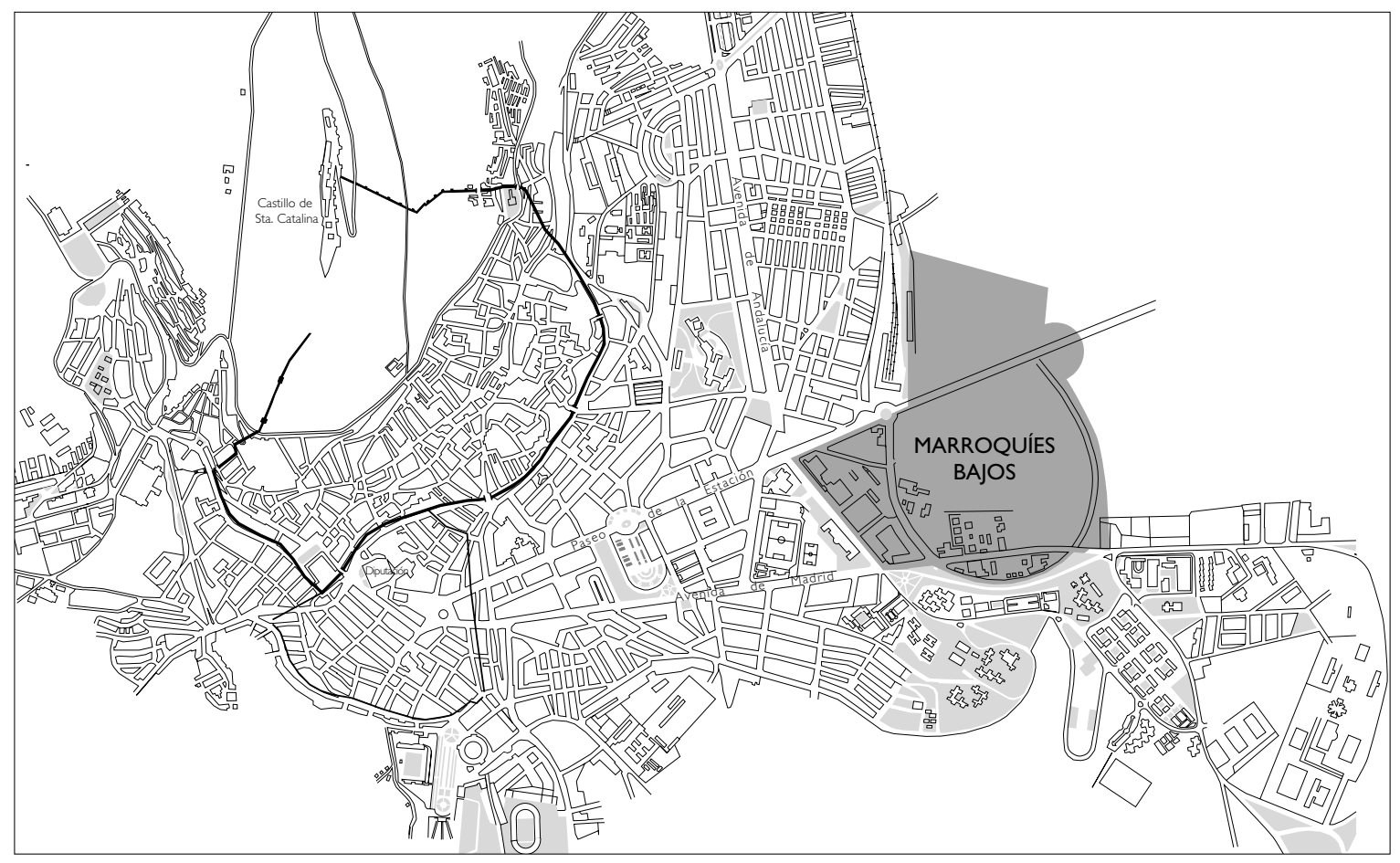

Fig. I. Plano de situación.

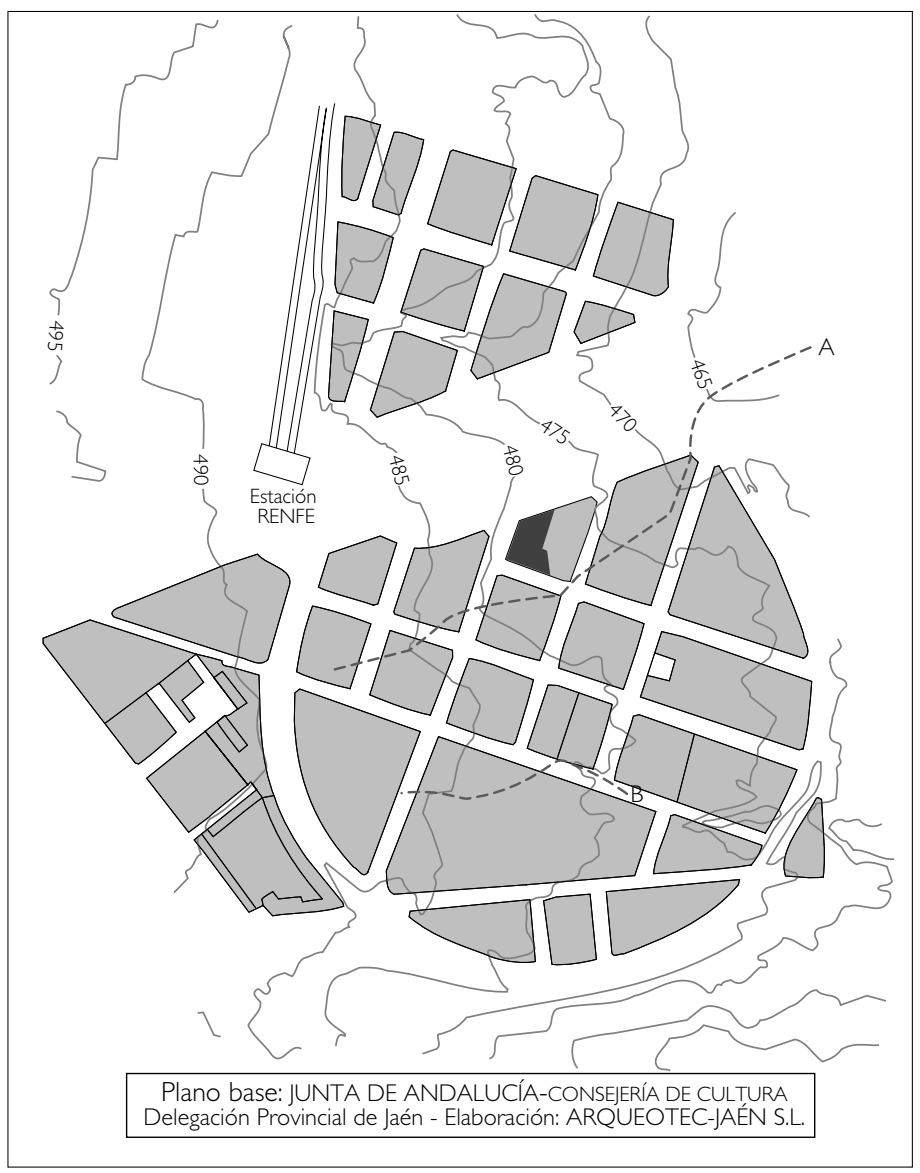

Fig. 2. Ubicación del solar. 


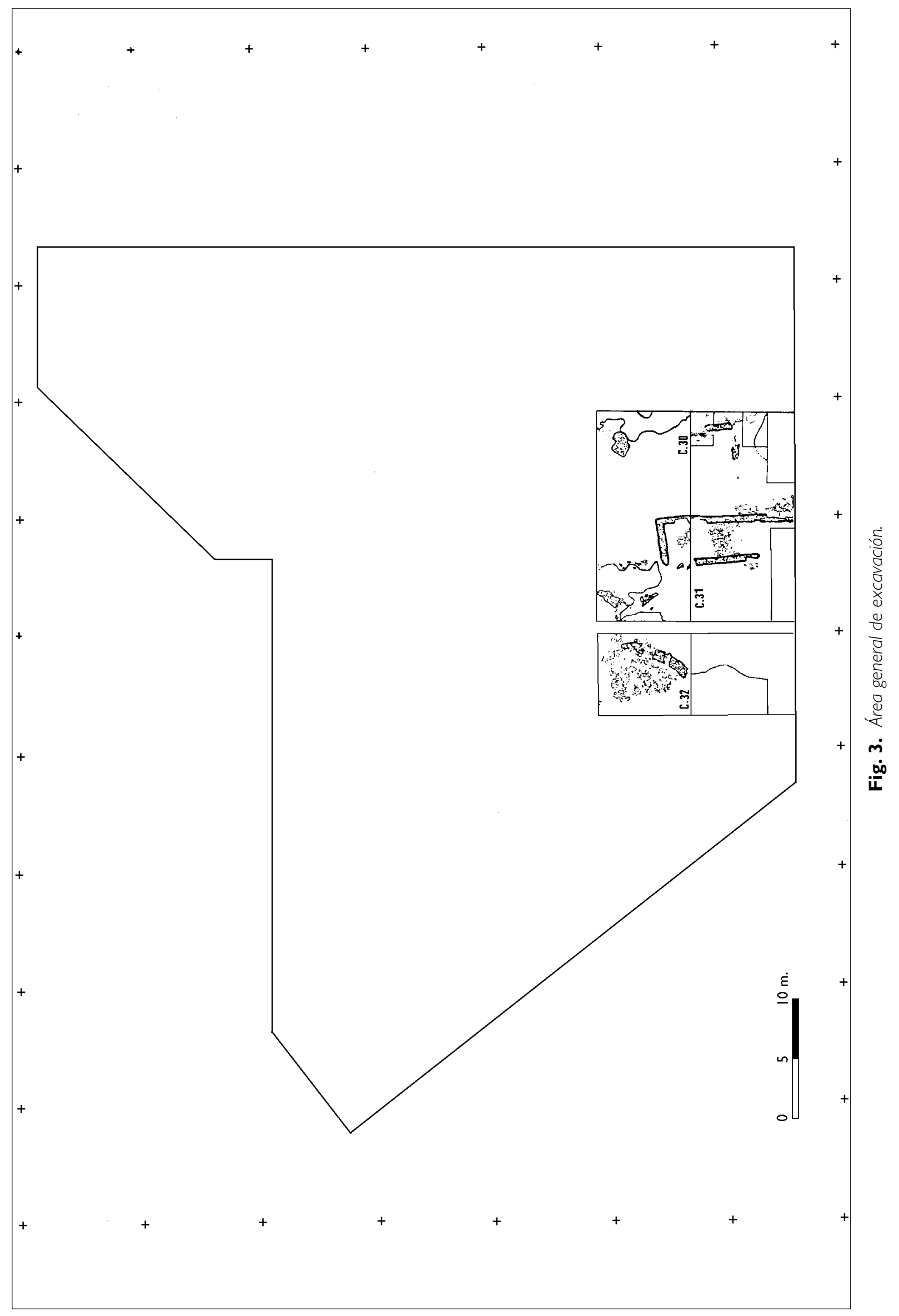




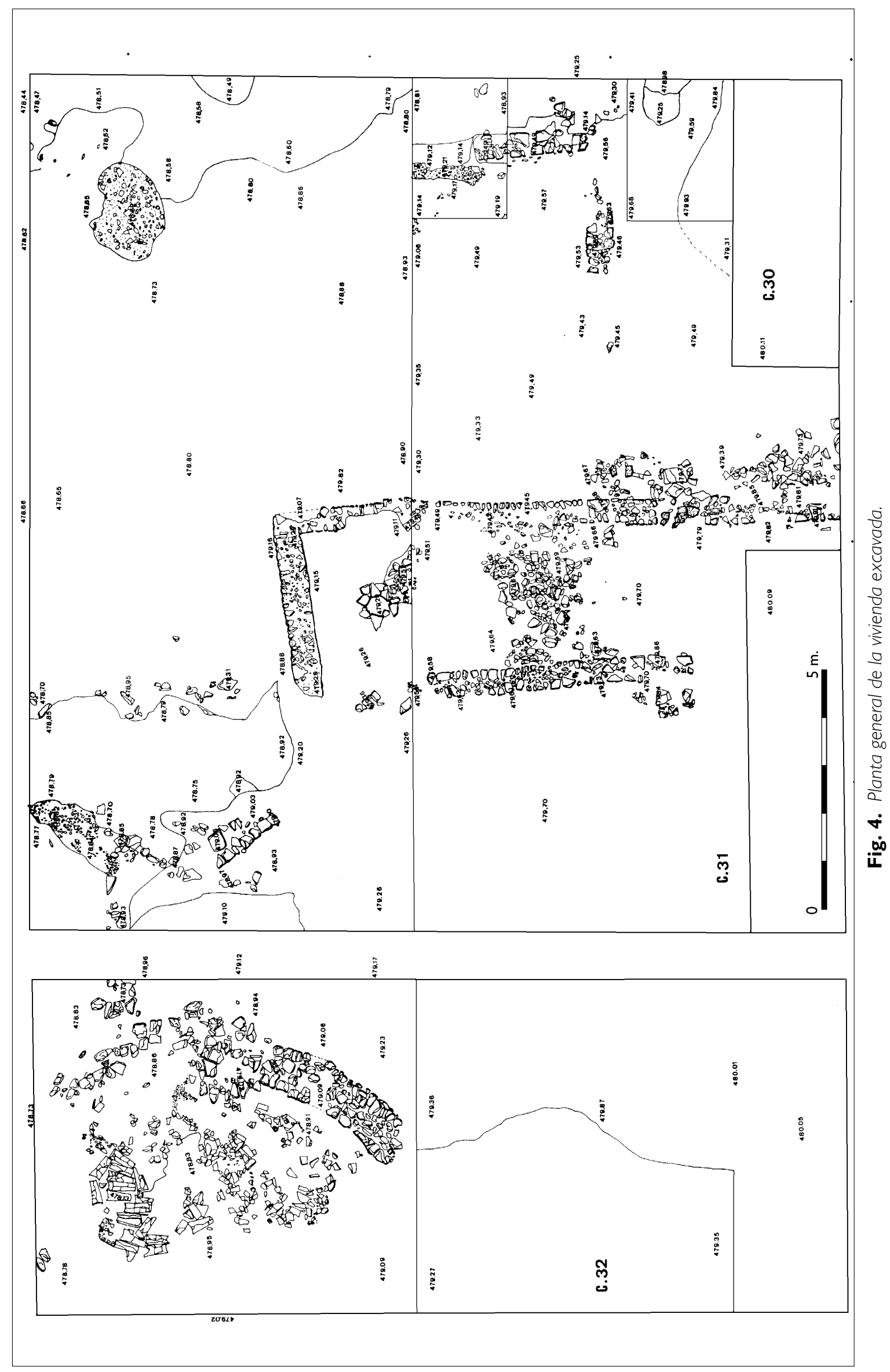




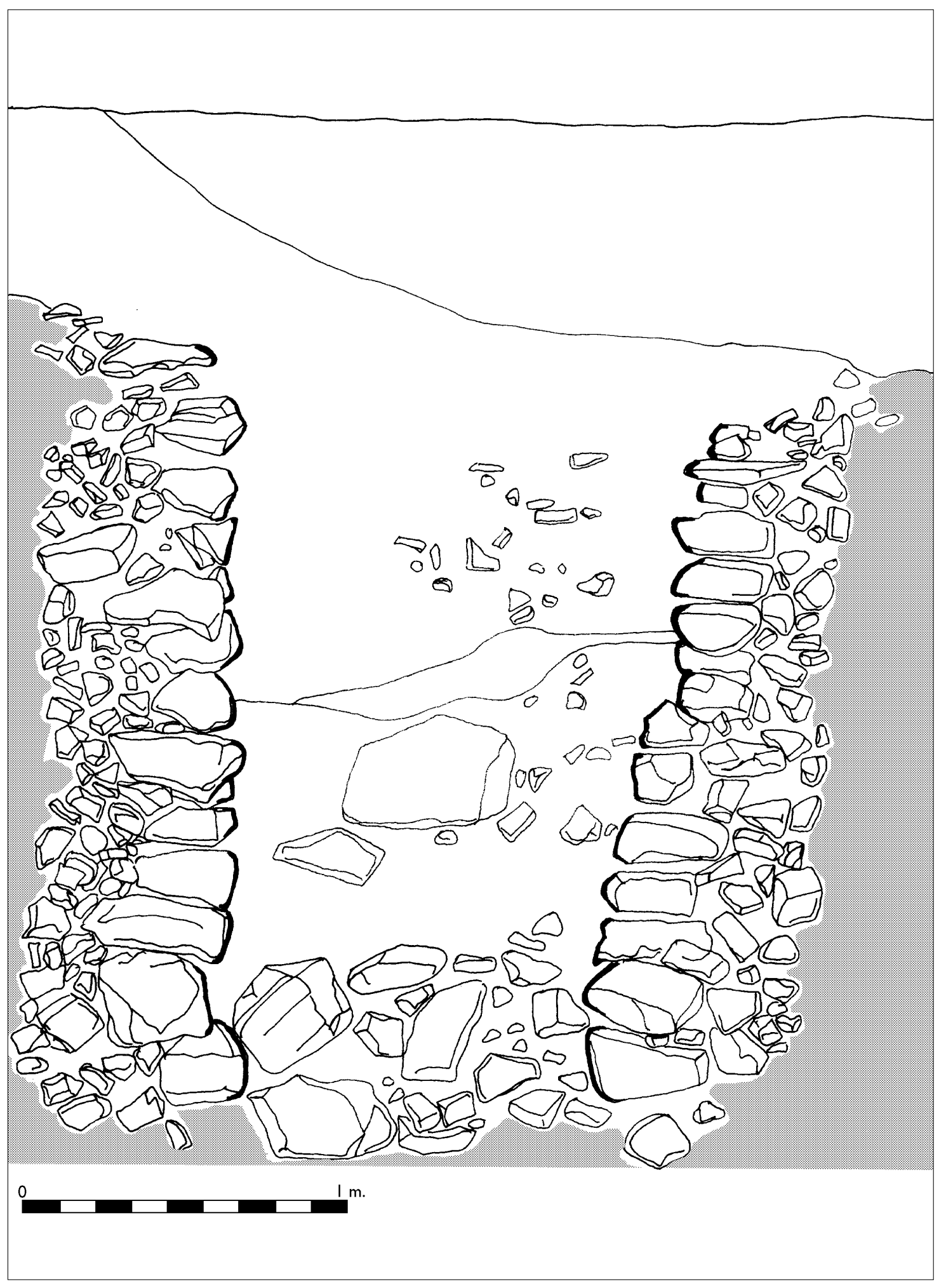

Fig. 5. Perfil del pozo de noria. 


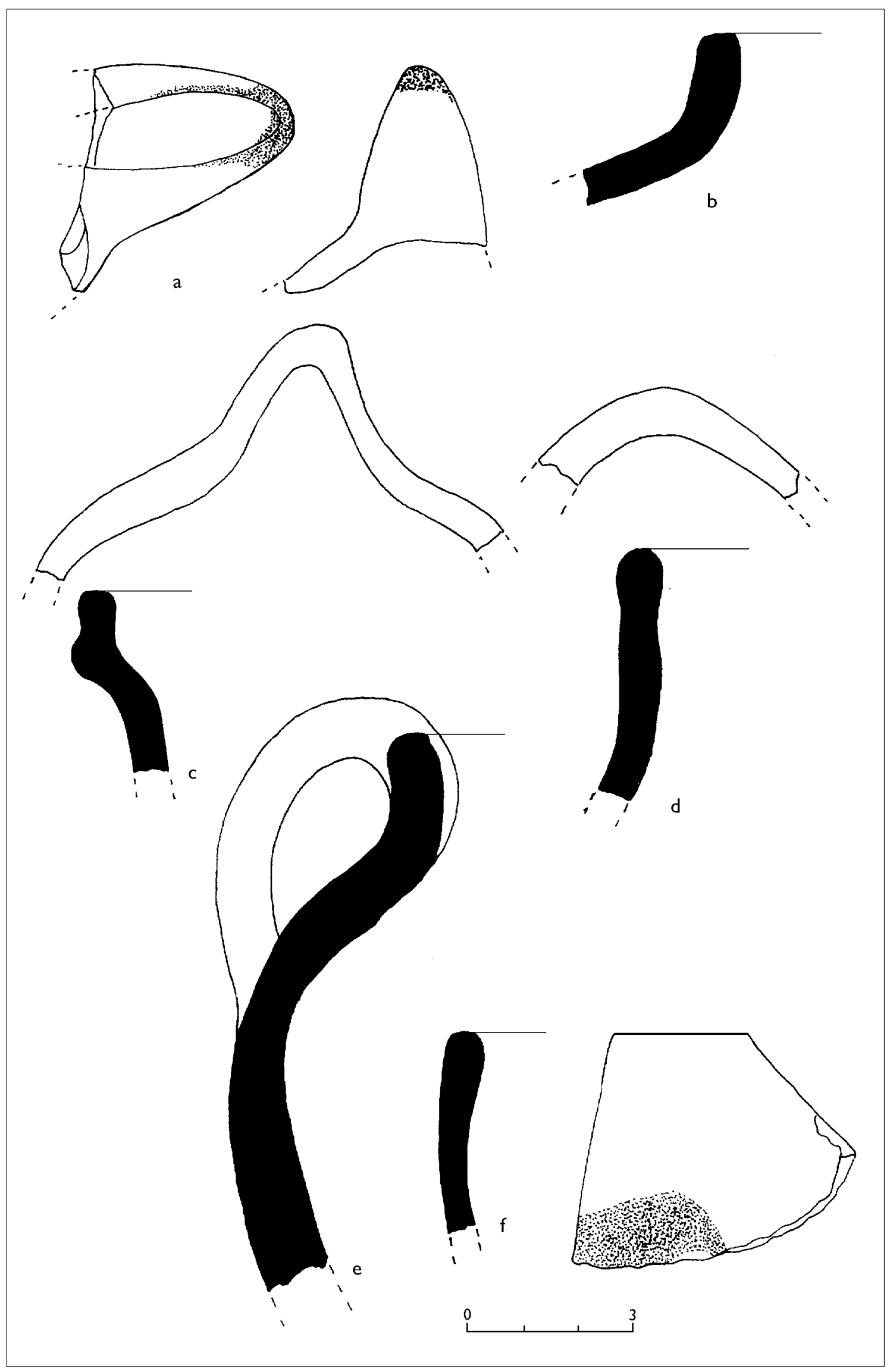

Fig. 6. Material de la primera fase emiral. 


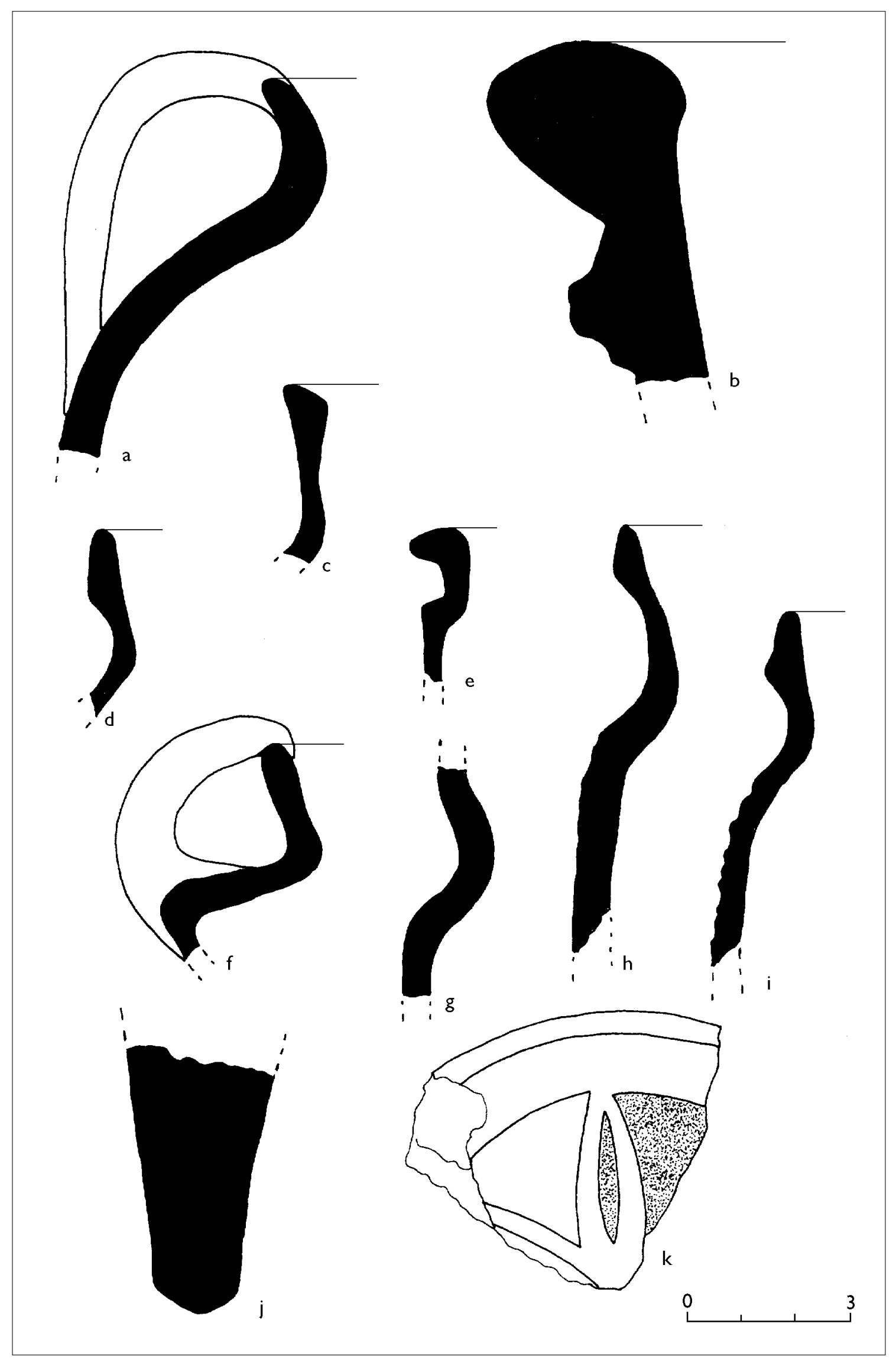

Fig. 7. Material cerámico y decorativo. Segunda fase de ocupación. 


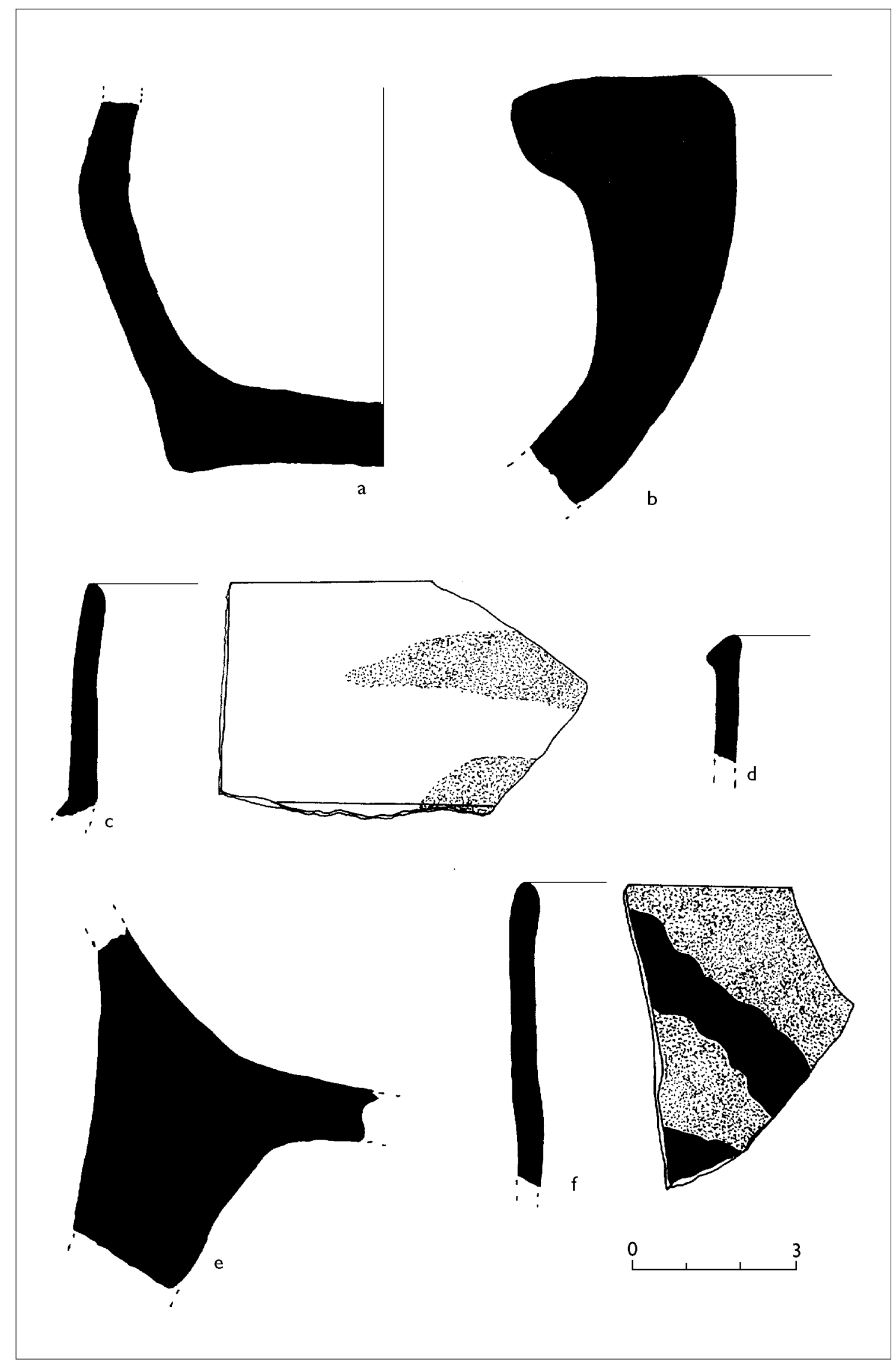

Fig. 8. Material cerámico. Segunda fase de ocupación. 


$$
\prod_{1}^{1}
$$




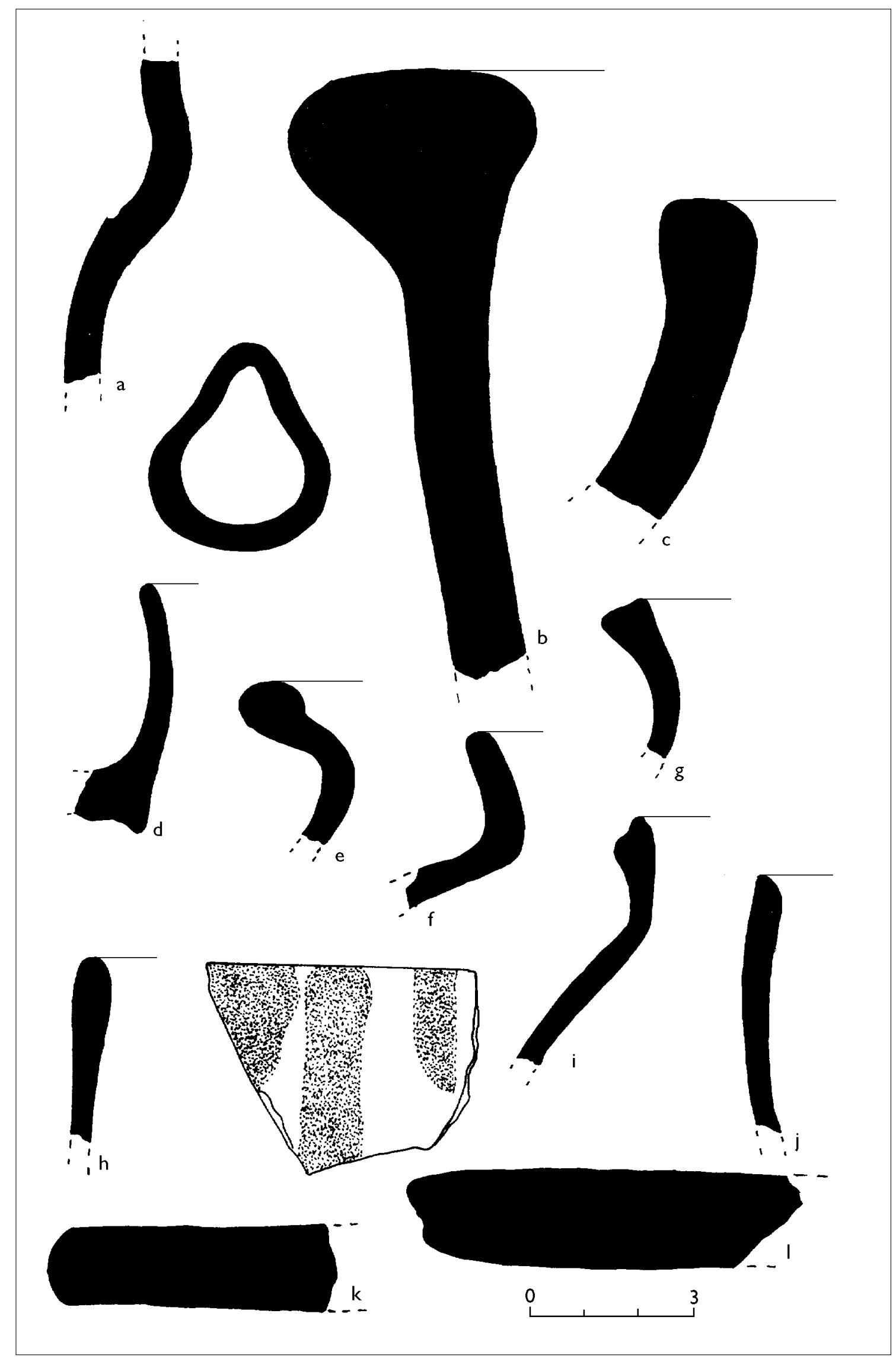

Fig. 10. Material cerámico. Segunda fase de ocupación. 


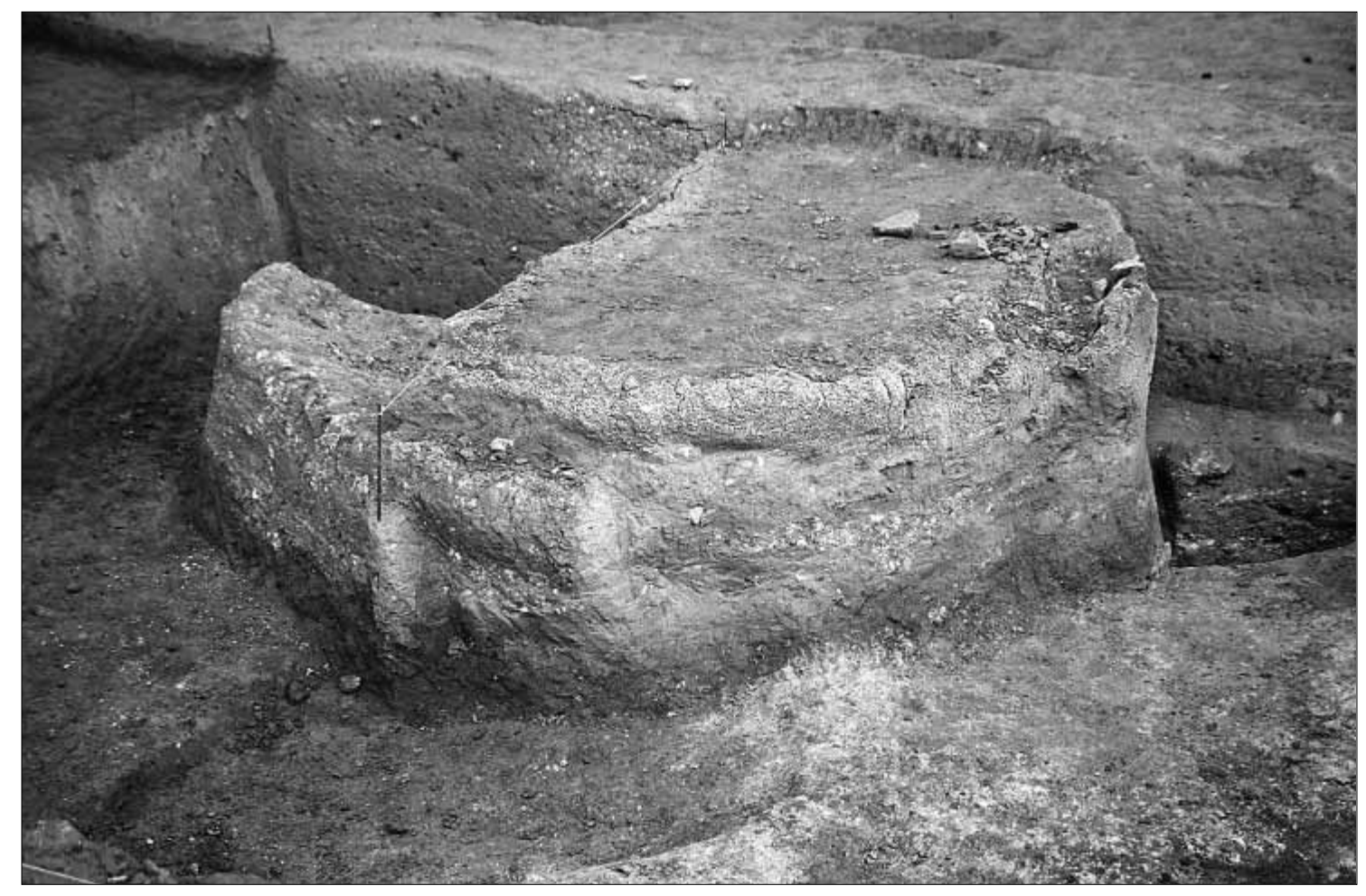

Lám. I. Estructura de la primera fase emiral.

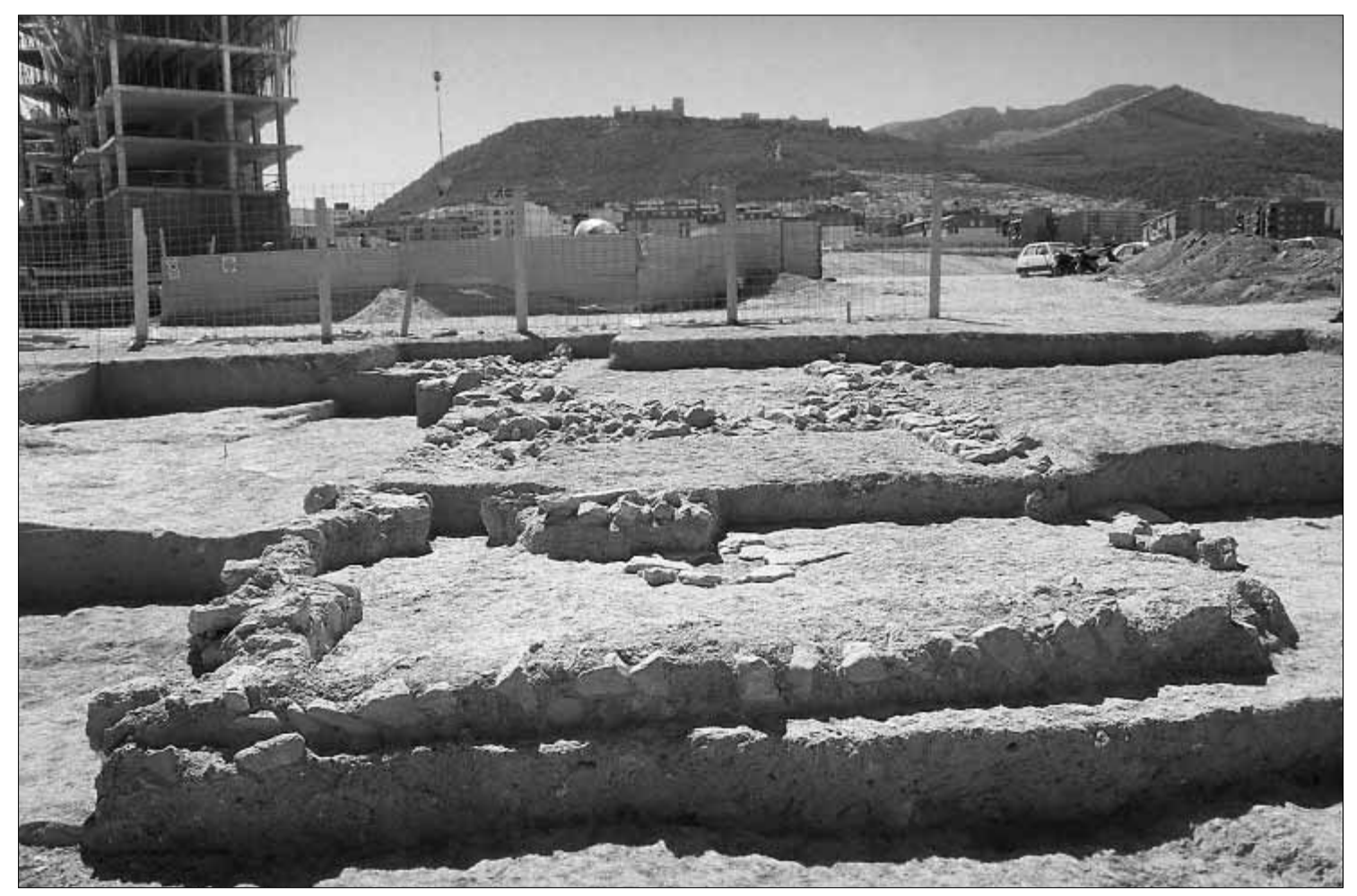

Lám. 2. Vista general de la vivienda. 


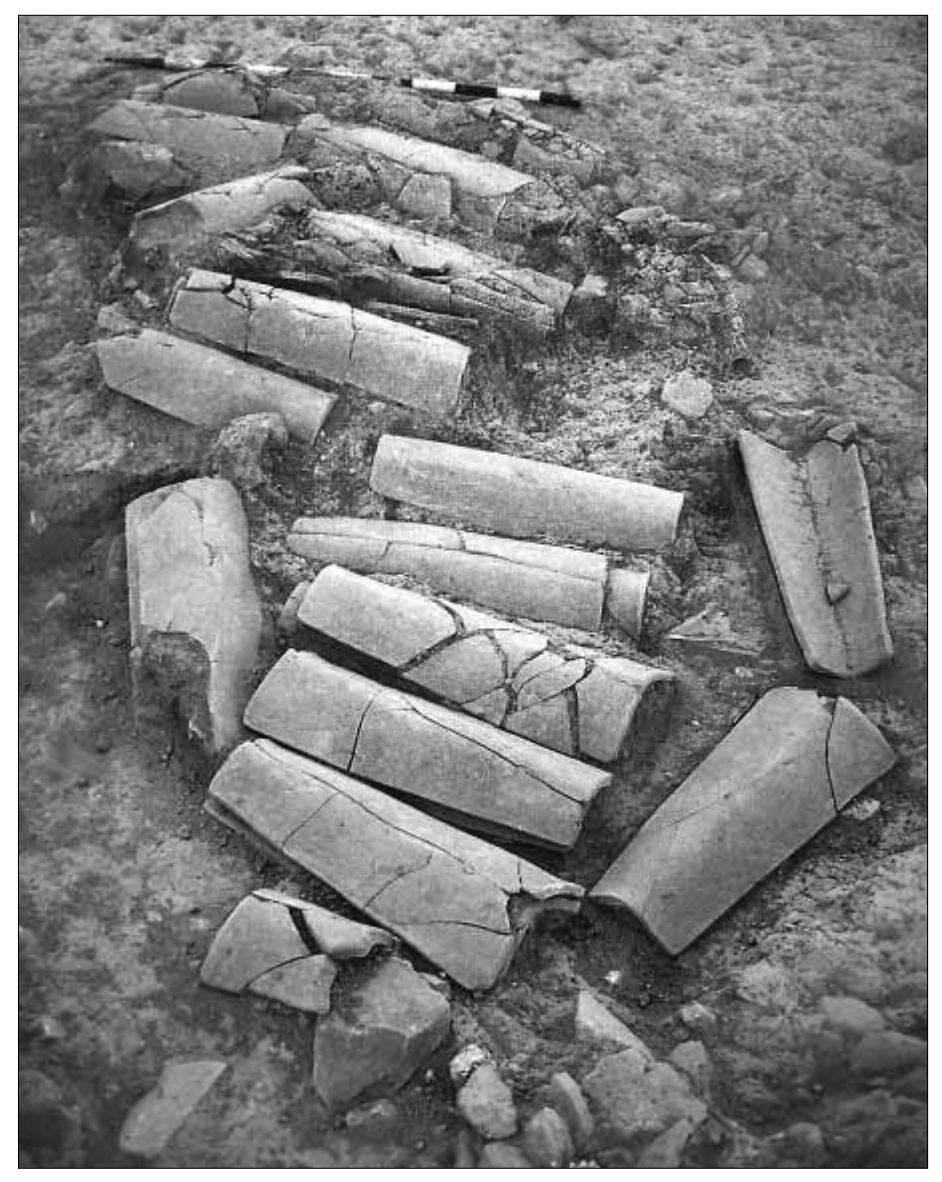

Lám. 3. Acumulación de tejas en

la proximidad de la casa emiral.

inge

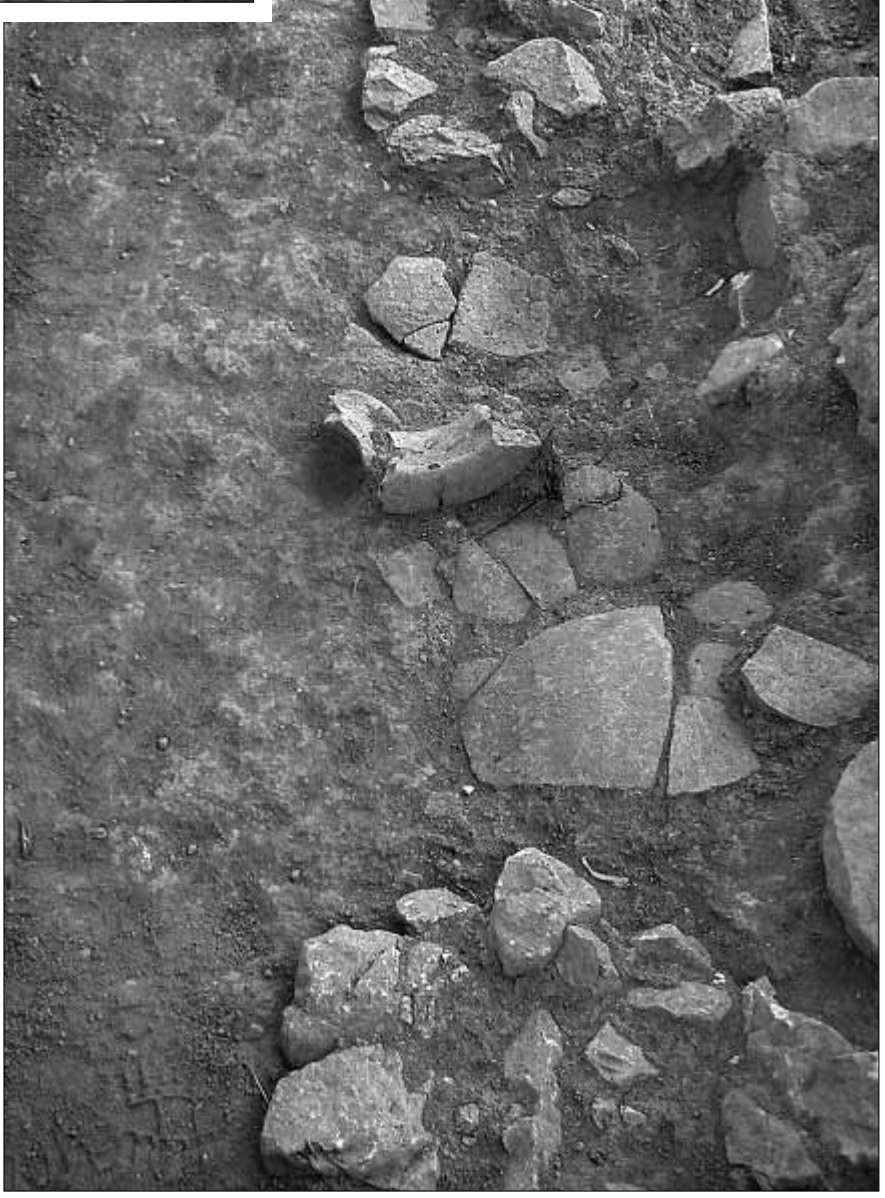

Lám. 4. Gran vasija fragmentada

dentro de la casa, obstruyendo una entrada de la misma. 
Lám. 5. Fosa rellena de restos cerámicos.
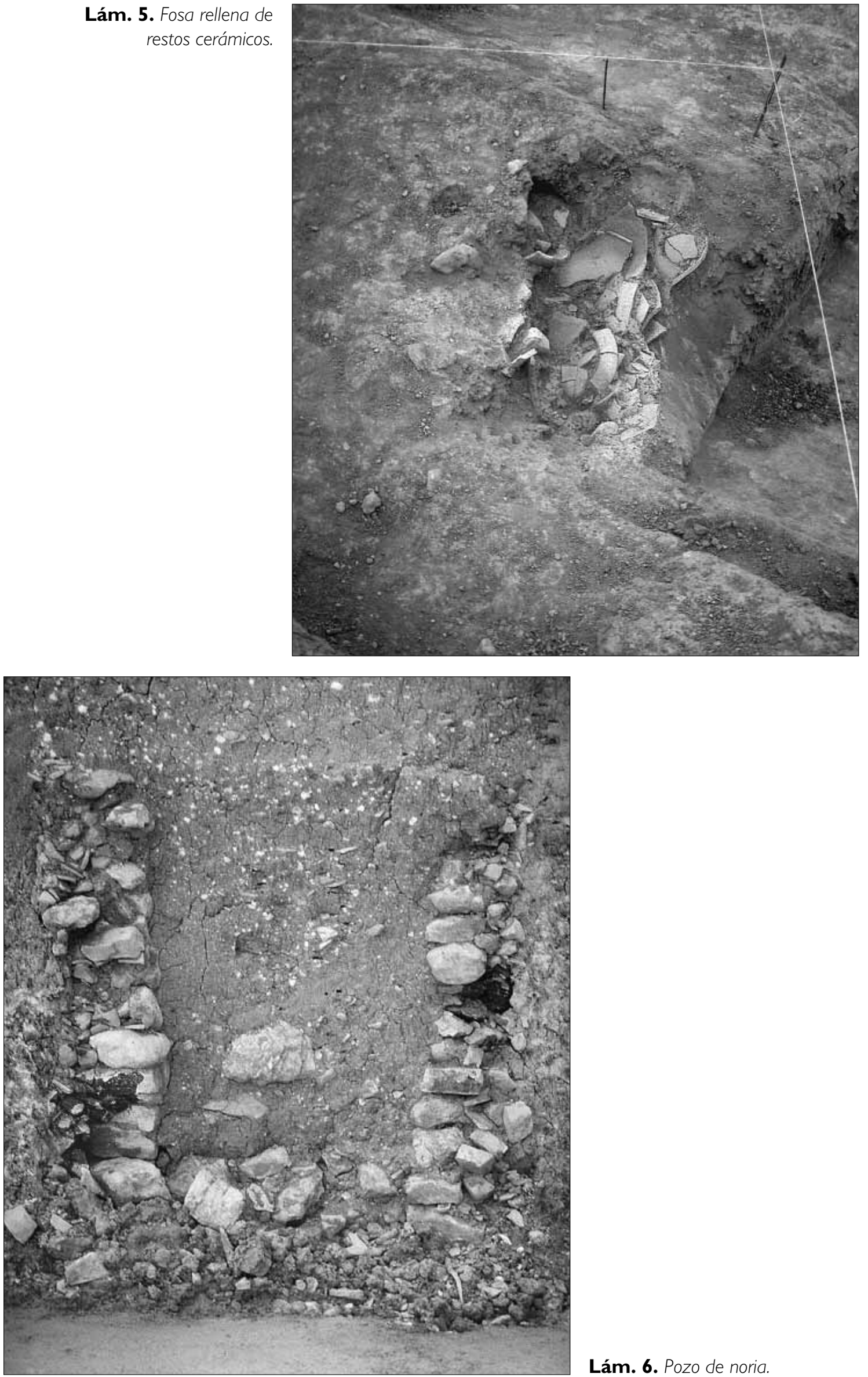

Lám. 6. Pozo de noria. 